\title{
Analysis of Large-Strain Consolidation Behavior of Soil with High Water Content in Consideration of Self-Weight
}

\author{
Yupeng Cao $\mathbb{D}^{1},{ }^{1}$ Jian Yang $\mathbb{D},{ }^{1}$ Guizhong $X u\left(\mathbb{D},{ }^{2}\right.$ and Jianwen $X u \mathbb{D}^{1}$ \\ ${ }^{1}$ College of Transportation, Shandong University of Science and Technology, No. 579, Qianwan'gang Road, Qingdao, \\ Shandong 266590, China \\ ${ }^{2}$ Geotechnical Research Institute, Yancheng Institute of Technology, No. 9, Xiwang Road, Yancheng, Jiangsu 224051, China
}

Correspondence should be addressed to Yupeng Cao; paradise456917@163.com

Received 20 April 2018; Revised 3 July 2018; Accepted 13 August 2018; Published 20 September 2018

Academic Editor: Xinbao Yu

Copyright (c) 2018 Yupeng Cao et al. This is an open access article distributed under the Creative Commons Attribution License, which permits unrestricted use, distribution, and reproduction in any medium, provided the original work is properly cited.

Based on the axisymmetric large-strain consolidation (ALSC) model with the void ratio as the variable under equal strain condition, difference schemes of model's equation, initial condition, and boundary condition were given. Taking phosphatic clay in Florida as a research object, the consolidation behaviors of soil with high water content by axisymmetric large-strain theory and one-dimensional large-strain theory were analyzed. The effect of different kinds of consolidation theories and self-weight stress on an average degree of consolidation was evaluated. The development of the void ratio and excess pore water pressure along the soil layer was clarified. The results show that the theoretical value of Terzaghi's consolidation degree is always less than that of ALSC $\left(U_{s}\right.$, the average degree of consolidation defined by strain)-vertical drainage in the consolidation process. Terzaghi's solution overestimates the dissipation rate of excess pore water pressure during the earlier consolidation period but underestimates it during the later consolidation period. The degree of consolidation calculated by Hansbo develops faster than ALSC ( $U_{\mathrm{p}}$, the average degree of consolidation defined by stress)-radial drainage, but slower than ALSC $\left(U_{\mathrm{s}}\right)$-radial drainage. In the ALSC model, $U_{\mathrm{s}}$ is always been faster than $U_{\mathrm{p}}$. The effect of self-weight on the consolidation degree of axisymmetric large-strain consolidation theory is relatively small (maximum error is less than 16\%), while it can accelerate the consolidation rate of soil in onedimensional large-strain consolidation theory largely. When only the vertical drainage occurs, the consolidation rate in the middle of the soil is obviously lagging the upper and lower parts, while the radial drainage can reduce the void ratio and the excess pore water pressure along the soil layer uniformly and more rapidly.

\section{Introduction}

In dredging projects, such as port and dock construction projects, the treatment of large-area soft soils is often encountered. Due to the low permeability of soft soils, the consolidation rate under self-weight and applied loads is slow, and prefabricate vertical drains (such as plastic drainage boards) are often used in the site works to speed up the consolidation process of soil. Consolidation with the vertical drainage body in soft soil can be simplified as a single well consolidation problem. Axisymmetric consolidation theory proposed by Barron [1] is widely accepted, and the degree of soil's consolidation can be predicted by analytical or numerical methods. The consolidation properties of soil can be revealed by this theory. Over the years, based on Barron's axial symmetry consolidation theory, the in-depth study of soil consolidation behavior was carried out from many aspects, such as well resistance and smearing [2-5], loading changes over time [6-10], nonlinear compression and penetration parameters $[11,12,13]$, negative pressure loading $[14,15,16,17]$, and multi-layer $[18,19]$. It provides theoretical support for design and calculation of the consolidation method with vertical drains in practical projects.

However, the accuracy of prediction and analysis of soil consolidation behavior is not only related to the parameters used in the model and calculation methods but also essentially related to the consolidation model itself. When using the above-mentioned theoretical models for 
consolidation analysis of supersoft foundations, especially those with high water ocean soft soils or dredged soils that are in a flow state, there is a big difference between the theoretical and the field values [20]. This is mainly because these theoretical models are all based on the assumption of small strain, without considering the effect of large geometric strains.

Fox et al. [21] used a series of small-strain calculations to perform large-strain radial consolidation analysis by displacement-corrected coordinates. However, the variation of material nonlinearity with geometric large deformation was not considered. Indraratna et al. [22] analyzed the largestrain consolidation behavior considering radial nonlinear flow and non-Darcy's law under vacuum loading without considering vertical seepage. Jiang et al. [20] coupled geometric nonlinearity and material nonlinearity, considering vertical and radial simultaneous seepage, and expanded Gibson's one-dimensional large-strain consolidation theory to axisymmetric large-strain consolidation theory. More recently, Zhang et al. [23], Hu et al. [24], and Sun et al. [25] studied the sand-drained large-strain consolidation model with double-layer foundations, creep, and partially penetrated sand wells, respectively. Although the smearing effect controls the consolidation rate of soil [3], its effect on consolidation properties cannot be quantitatively described by these theories.

It should be pointed out that the above-mentioned theory of large-strain consolidation is under free-strain conditions (equal stress consolidation). Some scholars believe that under axisymmetric consolidation, the soil is closer to the state of free strain [7]. From the perspective of practical engineering, some scholars have pointed out that equal settlement is easier to achieve in the project because the horizontal spacing of vertical drainage bodies is the same [21]. The soil consolidation near the sand well is fast, which will cause the contact stress redistribution [26]. It is undeniable that results from the equal strain solutions and the free-strain solutions are very close $[1,3,7,27]$. The theoretical solution based on the equal strain hypothesis is relatively simple. It can also easily reflect the effect of soil compression characteristics on consolidation in smeared and undisturbed zones. At present, researchers generally assume that the consolidation problem of sand wells is an equal vertical strain problem [26]. In order to facilitate the comparative analysis of large- and small-strain consolidation theories, Cao et al. [28, 29] established the axisymmetric large-strain consolidation model in positive loading pressure (named ALSC) and negative vacuum pressure (named NALSC) with the void ratio as the variable under equal strain condition and verified the validity of these models.

The axisymmetric large-strain consolidation theory breaks through the small-strain theoretical framework and can accurately analyze the settlement characteristics of soils. However, the focus of researchers is mainly on verifying the theory through numerical or analytical solutions or on the development of consolidation rate [20,23, 24, 25, 28, 29]. Very few studies investigated the difference between axisymmetric large-strain and small-strain theories considering self-weight stress. Also, the effect of gravity stress and radial drainage on the large-strain consolidation characteristics was not adequately investigated, especially for underconsolidated dredged soils with high water content.

In this study, based on the ALSC model, difference schemes of the consolidation equation, initial conditions, and boundary conditions were included. Taking the phosphatic clay in Florida as a research object [30], vertical drainage bodies were arranged based on scenario C (quiescent consolidation and surcharge loading of a pond having a uniform initial void ratio) to investigate the consolidation behavior of soils with high water content. The difference between the calculated values of large- and small-strain under axial symmetry and one-dimensional consolidation theory was analyzed. The influence of self-weight on the average degree of consolidation was considered. The variation of the void ratio and excess pore water pressure along soil height and consolidation time under different drainage modes was studied.

\section{ALSC Model}

Figure 1 shows the schematic representation of the case of a circular soil cylinder where a vertical drain is surrounded by a smeared zone and undisturbed soil. The soil has an initial layer thickness $L$, and it is freely draining at the top and impermeable at the bottom. The center of the cylinder contains a vertical drain well of radius $r_{\mathrm{w}}$ surrounded by a zone of remolded soil by radius $r_{s}$. The smear zone is surrounded by undisturbed soil with a radius of influence $r_{\mathrm{e}}$. Let $k_{\mathrm{s}}$ and $k_{\mathrm{h}}$ represent the horizontal permeability of the smear zone and undisturbed zone, respectively, and $k_{\mathrm{v}}$ represent the vertical permeability of soil.

The convective coordinate $\xi$ measured downwards in the direction of gravity is the same with one-dimensional largestrain consolidation. The Euler polar coordinates $(r, \theta)$ are used for radical flows, where $r$ is measured away from the drain (Figure 2). $Q_{1}$ and $Q_{2}$ represent the vertical pore water inflow and outflow of the unit cell in the soil at a unit time, respectively. $Q_{3}$ and $Q_{4}$ represent the radial pore water inflow and outflow of the unit cell in the soil at a unit time, respectively.

Coupled flow equation, continuous equation of the saturated soil, stress balance equation, effective stress principle, etc. [28] established the ALSC model with the void ratio as variable under equal strain station. The model accounts for smear effect, soil self-weights, radial and vertical flows, and variable permeability and compressibility during the consolidation progress. Well resistance is not considered. The consolidation equation is expressed as shown in the following equation:

$$
\begin{gathered}
\frac{\partial e}{\partial t}-\left(G_{\mathrm{s}}-1\right) \frac{d}{d e}\left(\frac{k_{\mathrm{v}}}{1+e}\right) \frac{\partial e}{\partial z}+\frac{\partial}{\partial z}\left[\frac{k_{\mathrm{v}}}{\gamma_{\mathrm{w}}(1+e)} \frac{d \sigma^{\prime}}{d e} \frac{\partial e}{\partial z}\right] \\
=-\frac{8 k_{\mathrm{h}}(1+e)}{\gamma_{\mathrm{w}} d_{\mathrm{e}}^{2} \mu}\left[\left(G_{\mathrm{s}}-1\right) \gamma_{\mathrm{w}} z-\sigma^{\prime}+q\right],
\end{gathered}
$$

where $G_{s}$ is the specific gravity of the solid particles, $\gamma_{\mathrm{w}}$ is the unit weight of water, $q$ is the loading pressure; $n$ is the ratio 


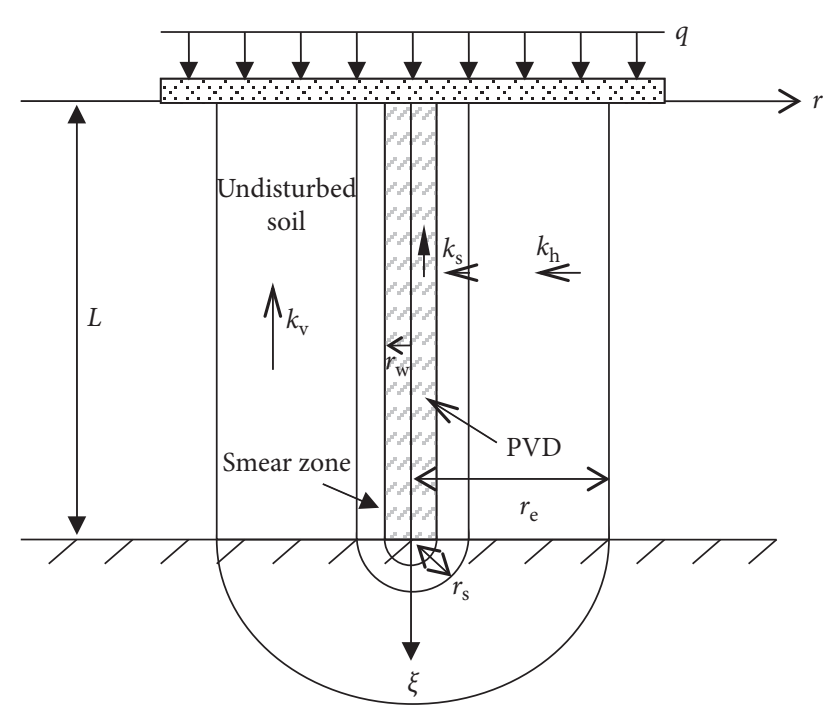

FIGURE 1: Schematic diagram of the typical cylindrical cell.

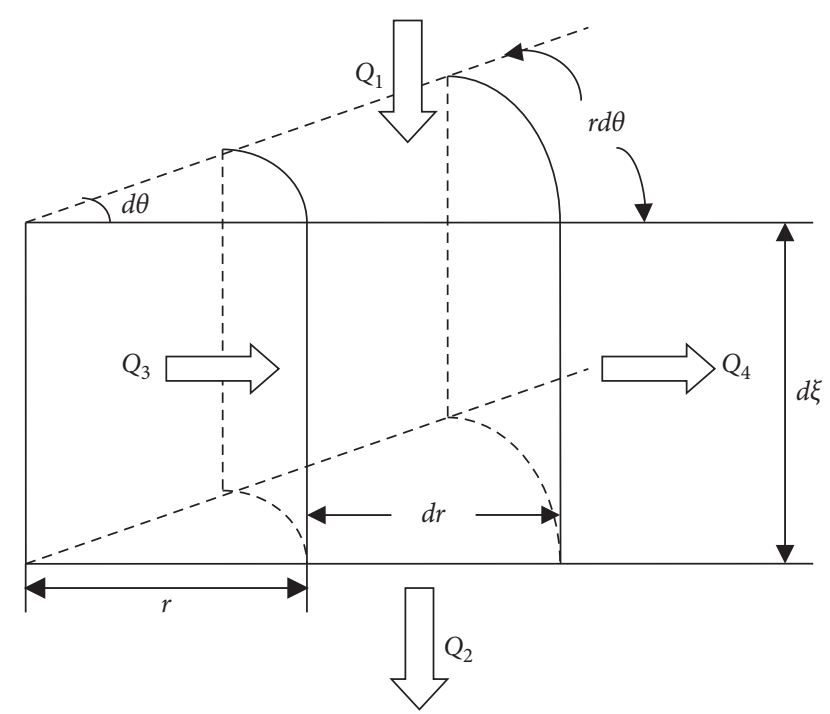

Figure 2: The diagram of coordinates systems.

$r_{\mathrm{e}} / r_{\mathrm{w}}, s$ is the ratio $r_{\mathrm{s}} / r_{\mathrm{w}}, \sigma^{\prime}$ is the effective vertical stress, $e$ is the void ratio, $z$ is the spatial vertical coordinates in the Lagrange coordinate system, and $d_{\mathrm{e}}$ is the diameter of influence. $\mu$ is expressed as follows:

$$
\begin{aligned}
\mu= & \frac{n^{2}}{\left(n^{2}-1\right)}\left(\ln \frac{n}{s}-\frac{3}{4}+\frac{k_{\mathrm{h}}}{k_{\mathrm{s}}} \ln s\right)+\frac{s^{2}}{n^{2}-1}\left(1-\frac{s^{2}}{4 n^{2}}\right) \\
& +\frac{k_{\mathrm{h}}}{k_{\mathrm{s}}} \frac{1}{n^{2}-1}\left(\frac{s^{4}-1}{4 n^{2}}-s^{2}+1\right) .
\end{aligned}
$$

Equation (1) is based on the following assumptions:

(1) The soil is completely homogeneous and watersaturated.

(2) Solid particles and water are incompressible, and the deformation of the soil is completely caused by the discharge of pore water.
(3) The vertical and radial flows obey Darcy's law, and the coefficient of permeability changes with the void ratio during the consolidation.

(4) All compressive strains within the soil occur in a vertical direction. The soil particles do not move along the radial and tangential directions, and no creep is considered.

(5) Horizontal sections remain horizontal during the consolidation.

(6) All vertical loads are applied instantaneously, and the load distribution is uniform over the whole cylindrical area.

The above assumptions remove the limits of small-strain hypothesis of soil. The vertical nonlinear compression characteristics, nonlinear permeability for radial and vertical flows, and skeleton deformation generated by vertical movement of soil particles are considered in model ALSC. Therefore, geometric nonlinearity and material nonlinearity are brought into equal strain consolidation for large-area loading condition, which agrees well with the settlement law with vertical drain in real engineering problems. Equation (1) can be rewritten into the one-dimensional large-strain consolidation equation as given by Gibson et al. [31, 32] by ignoring the horizontal radial flow (i.e., $k_{\mathrm{h}}=0$ ).

If the assumption of small strain is considered, and there is no vertical flow (i.e. $k_{\mathrm{v}}=0$ ), Equation (1) can be rewritten into the axisymmetric consolidation control equation as given by Hansbo [3].

\section{Difference Schemes of the ALSC Model}

As it can be seen, the theoretical model of formula (1) is a highly complex nonlinear equation, and it is difficult to solve it analytically. The finite difference method can be used for calculation and analysis. For convenience, Equation (1) can be written as

$$
\frac{\partial e}{\partial t}=\frac{\partial}{\partial z}\left[g(z, t) \frac{\partial e}{\partial z}\right]+B(z, t) \frac{\partial e}{\partial z}-C(z, t)-D(z, t),
$$

where,

$$
\begin{aligned}
& g(z, t)=-\frac{k_{\mathrm{v}}}{\gamma_{\mathrm{w}}(1+e)} \frac{d \sigma^{\prime}}{d e} \\
& B(z, t)=\left(G_{\mathrm{s}}-1\right)\left[\frac{1}{1+e} \frac{d k_{\mathrm{v}}}{d e}-\frac{k_{\mathrm{v}}}{(1+e)^{2}}\right] \\
& C(z, t)=\frac{8 k_{\mathrm{h}}(1+e)}{\gamma_{\mathrm{w}} d_{\mathrm{e}}^{2} \mu}\left(G_{\mathrm{s}}-1\right) \gamma_{\mathrm{w}} z \\
& D(z, t)=\frac{8 k_{\mathrm{h}}(1+e)}{\gamma_{\mathrm{w}} d_{\mathrm{e}}^{2} \mu}\left(-\sigma^{\prime}+q\right)
\end{aligned}
$$

Each of Equations (4)-(7) has its own unique parameters and perform different consolidation behavior. $B(z, t)$ and $C(z, t)$ constitute the gravity item, $D(z, t)$ is relevant to the radial drainage, and $g(z, t)$ represents the coefficient of onedimensional large-strain consolidation. 
Equation (3) is a variable coefficient convectiondiffusion equation, $B(z, t), C(z, t), D(z, t)$, and $g(z, t)$ all have upper and lower limits, such as $0<v \leq g(z, t) \leq f$, $0 \leq C(z, t) \leq f, 0 \leq D(z, t) \leq f$, and $|B(z, t)| \leq f$.

Let $\Delta z$ and $\Delta t$ represent the space step and time step, respectively, $z_{i}=i \Delta z, i=0,1,2, \ldots, I$ and $t_{j}=$ $j \Delta t, j=0,1,2, \ldots, J$. The difference scheme is like the convection-diffusion equation with constant coefficients. According to the upwind difference scheme, Equation (3) can be written in the following format, and the discrete schematic diagram of space and time is shown in Figure 3:

$$
\begin{aligned}
\frac{e_{i}^{j+1}-e_{i}^{j}}{\Delta t}= & \frac{1}{\Delta z^{2}}\left[g_{i+1 / 2}^{j}\left(e_{i+1}^{j}-e_{i}^{j}\right)-g_{i-1 / 2}^{j}\left(e_{i}^{j}-e_{i-1}^{j}\right)\right] \\
& +\frac{B_{i}^{j}+\left|B_{i}^{j}\right|}{2} \frac{e_{i+1}^{j}-e_{i}^{j}}{\Delta z}+\frac{B_{i}^{j}-\left|B_{i}^{j}\right|}{2} \frac{e_{i}^{j}-e_{i-1}^{j}}{\Delta z}-C_{i}^{j}-D_{i}^{j},
\end{aligned}
$$

where

$$
\begin{aligned}
g_{i \pm 1 / 2}^{j} & =\frac{1}{2}\left(g_{i}^{j}+g_{i \pm 1}^{j}\right), \\
g_{i}^{j} & =-\frac{k_{i}^{j}}{\gamma_{\mathrm{w}}\left(1+e_{i}^{j}\right)}\left[\frac{d \sigma^{\prime}}{d e}\right]_{i}^{j}, \\
B_{i}^{j} & =\left(G_{\mathrm{s}}-1\right)\left\{\frac{1}{1+e_{i}^{j}}\left[\frac{d k_{\mathrm{v}}}{d e}\right]_{i}^{j}-\frac{k_{\mathrm{v} i}^{j}}{\left(1+e_{i}^{j}\right)^{2}}\right\}, \\
C_{i}^{j} & =\frac{8 k_{\mathrm{hi}}^{j}\left(1+e_{i}^{j}\right)}{\gamma_{\mathrm{w}} d_{\mathrm{e}}^{2} \mu}\left(G_{\mathrm{s}}-1\right) \gamma_{\mathrm{w}} i \Delta z, \\
D_{i}^{j} & =\frac{8 k_{\mathrm{hi}}^{j}\left(1+e_{i}^{j}\right)}{\gamma_{\mathrm{w}} d_{\mathrm{e}}^{2} \mu}\left(-\sigma_{i}^{\prime j}+q\right) .
\end{aligned}
$$

Difference equations can better reflect the material nonlinear characteristics of soil, which is much closer to the actual situation than special assumptions of soil permeability and compressibility for obtaining analytical solutions easily. During the calculation, good results for any given form of $e-\sigma^{\prime}$ and $e-k$ will be obtained by substituting $k_{\mathrm{vi}}^{j}$, $\left[d k_{v} / d e\right]_{i}^{j},\left[d \sigma^{\prime} / d e\right]_{i}^{j}, \sigma_{i}^{\prime j}, k_{\mathrm{h} i}^{j}$ into $g_{i}^{j}, B_{i}^{j}, C_{i}^{j}, D_{i}^{j}$.

\section{Difference Schemes for Initial and Boundary Conditions}

Assume that the initial thickness of the high water-saturated homogeneous soil is $L$ (thickness $H$ in the spatial vertical coordinates in the Lagrange coordinate system, $\left.H=L /\left(1+e_{0}\right)\right)$. The initial void ratio $e_{0}$ at any position of soil for time zero is the same. Initial condition is described as

$$
e(z, 0)=e_{0} \quad(0 \leq z \leq H) .
$$

The difference scheme is given as

$$
e_{i}^{0}=e_{0} \text {. }
$$

The average void ratio $e(z, t)$ can be obtained from the relationship of effective vertical stress with the void ratio.

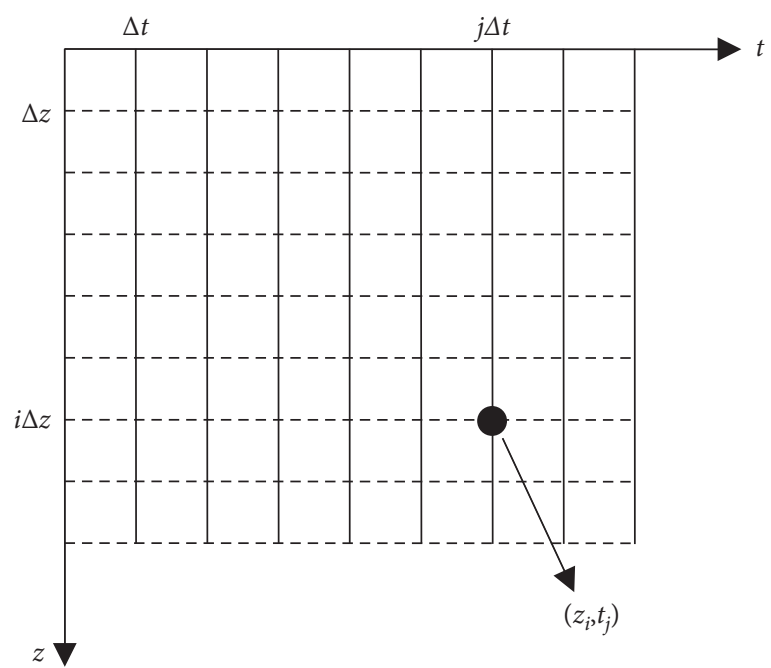

FIgURE 3: Discrete schematic diagram about the space and time.

The top of the soil is freely draining, and the excess pore water pressure dissipated instantaneously. According to the compression properties of soil, the final void ratio at the soil surface is given by

$$
e(0, t)=e_{f}(0) \quad(t>0) .
$$

The difference scheme for the upper boundary condition is given as

$$
e_{0}^{j}=e_{f}(0) \quad(t>0) .
$$

If the soil at the bottom is impermeable during the consolidation, the bottom boundary condition is determined as

$$
\left.\frac{\partial e}{\partial z}\right|_{z=L}=\left.\left(G_{\mathrm{s}}-1\right) \gamma_{\mathrm{w}} \frac{d e}{d \sigma^{\prime}}\right|_{z=H} .
$$

The difference scheme for the bottom boundary condition is given as

$$
\frac{e_{I+1}^{j}-e_{I}^{j}}{\Delta z}=\left.\left(G_{s}-1\right) \gamma_{w}\left[\frac{d e}{d \sigma^{\prime}}\right]_{i}^{j}\right|_{z=H} .
$$

\section{Case Analysis}

According to the ALSC model and the difference structure, the axisymmetric large-strain consolidation calculation program is compiled. Townsend and McVay [30] have described the predictions of ponds' (solids) elevation histories and one-year pore water pressure and void ratio profiles for four different wasted clay disposal scenarios (Scenario A: quiescent consolidation, uniform initial void ratio; Scenario B: stage filling, nonuniform initial void ratio; Scenario C: quiescent consolidation and surcharge loading of a pond having a uniform initial void ratio; and Scenario D: two-layer quiescent consolidation, sand/clay surcharge, and nonuniform initial void ratio). Station for Scenario C is closer to the assumptions (1) and (6) of the ALSC model, so Scenario $\mathrm{C}$ is selected for analysis. The nonlinear parameters, 
i.e., Equations (16) and (17), are used for prediction by nine different large-strain consolidation models. However, the predictions are varying from program to program:

$$
\begin{aligned}
& e=7.72\left(\sigma^{\prime}\right)^{-0.22}, \\
& k=0.2532 E-6 e^{4.65} .
\end{aligned}
$$

Figure 4 shows the quiescent consolidation with the top freely draining and impermeable at the bottom. The sludge is water-saturated and homogeneous. A $7.2 \mathrm{~m}$ deep waste pond with a uniform initial void ratio of 14.8 is capped with a $9.48 \mathrm{kPa}$ surcharge. The specific gravity of the solid particles is 2.82 . To illustrate the difference between large- and smallstrain consolidations with vertical drains, the PVD is quincunx arranged with the spacing of $1.0 \mathrm{~m}$ based on Scenario C. The width $(w) *$ thickness $(t)$ of the PVDs is $100 \mathrm{~mm} * 4 \mathrm{~mm}$. So, the equivalent radius of the vertical drain $(36.3 \mathrm{~mm})$ can be calculated according to the formula $r_{\mathrm{w}}=2(w+t) / \pi$ proposed by Hansbo [33]. The radius of influence $r_{\mathrm{e}}$ is set to $525 \mathrm{~mm}$. The large-strain material nonlinear parameters change with the void ratio seen in Equations (16) and (17), but the parameters of small-strain consolidation are the constant values. According to Equations (16) and (17), compressibility $a_{\mathrm{v}}$ shall be obtained at each level of the loading, and the vertical coefficient of consolidation $C_{\mathrm{v}}$ can be calculated from its definition. Assuming the soil is isotropy, we found the relationship $C_{\mathrm{v}}=C_{\mathrm{h}}$. The smearing is not considered during the simulation progress. The specific calculation parameters are shown in Table 1.

In the calculation program of the ALSC model, the soil is divided into 100 layers along the depth, and time step length is 0.1 day. Fifteen different kinds of simulations were performed, such as consolidation with or without self-weight, and only radial or vertical flows occurs. The whole computation time is 10000 days except for scenario "only vertical drainage without self-weight", where the time is 30000 days. The calculation parameters were obtained from [30]. The unit conversion is as follows: $1 \mathrm{ft}=304.8 \mathrm{~mm}$ and $1 \mathrm{psf}=47.88 \mathrm{~Pa}$.

In small-strain calculations, the time step is 1.0 day, the computation time of models "Hansbo" (which states that the axisymmetric small-strain consolidation theory of only radial flow is considered) and "Hansbo + Terzaghi" (which refers to that the vertical consolidation degree is calculated by Terzaghi's theory, the radial consolidation degree is calculated by Hansbo's theory, and then the average degree of consolidation is calculated according to Carrillo's theorem) is 10000 days. However, the computation time of model "Terzaghi" (which means computing by the Terzaghi classical one-dimensional small-strain consolidation theory-vertical flows only) needs 70000 days to achieve stablity.

\section{Differences of Average Degree of Consolidation between Large-Strain and Small-Strain Theories}

Figure 5 shows the average consolidation degree versus time for large- and small-strain consolidation theories.

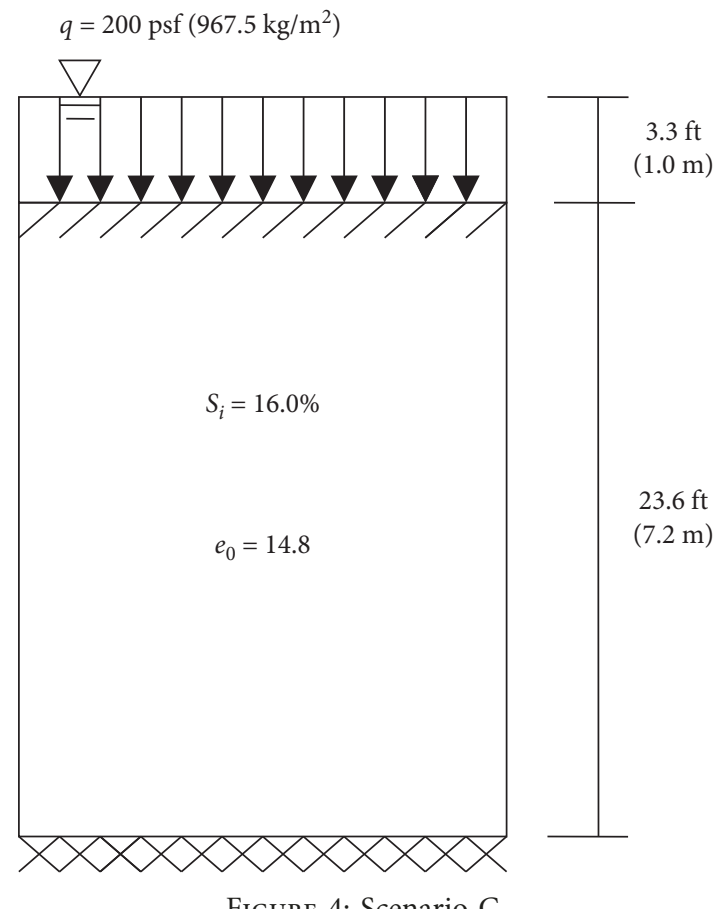

Figure 4: Scenario C.

"Double drainage" represents the simultaneous occurrence of vertical and radial flows, "radial drainage" indicates that only radial flow occurs ( $k_{\mathrm{v}}=0$, when calculating), and "vertical drainage" means that only vertical flows occur ( $k_{\mathrm{h}}=0$, when computing). In the calculation process, selfweight stress is considered, i.e., $G_{s} \neq 1$. At the same time, to reflect the difference between the settlement rate and the dissipating rate of excess pore water, the stress consolidation degree $U_{\mathrm{p}}$ (defined by stress) and the strain consolidation degree $U_{s}^{\mathrm{p}}$ (defined by strain) were calculated separately.

(1) The difference between one-dimensional consolidations. During the early stage of consolidation (within 1000 days), the degree of consolidation for Terzaghi's one-dimensional small-strain consolidation theory is faster than that for ALSC $\left(U_{\mathrm{p}}\right)$-vertical drainage. This is because the consolidation coefficient remains unchanged in Terzaghi theory. After 1000 days, the development of the Terzaghi consolidation degree is obviously lagging and is always less than that of ALSC $\left(U_{\mathrm{s}}\right)$-vertical drainage in the same consolidation time. This is because the large-strain theory considers the reduction in drainage distance during the consolidation process [34]. Terzaghi's solution overestimates the dissipation rate of the excess pore water pressure in the early consolidation stage and underestimates it during the later period. We can see from the consolidation stability time, the Terzaghi solution clearly overestimates the settling time of the soil. Take the degree of consolidation of $80 \%$ as an example. Terzaghi's theory needs 12853 days, while the time required for $\operatorname{ALSC}\left(U_{\mathrm{s}}\right)$-vertical drainage and ALSC $\left(U_{\mathrm{p}}\right)$-vertical drainage are 876 days and 3247 days, and the 
TABLE 1: Calculation parameters.

\begin{tabular}{lcccccccccc}
\hline Surcharge $(\mathrm{kPa})$ & Height $(\mathrm{m})$ & $G_{\mathrm{s}}$ & Initial void ratio, $e_{0}$ & $C_{\mathrm{v}} / 10^{-4} \mathrm{~cm}^{2}(\mathrm{~s})$ & $C_{\mathrm{h}} / 10^{-4} \mathrm{~cm}^{2}(\mathrm{~s})$ & $r_{\mathrm{w}}(\mathrm{mm})$ & $r_{\mathrm{e}}(\mathrm{mm})$ & $s$ & $k_{\mathrm{h}} / k_{\mathrm{s}}$ & $n$ \\
\hline 9.48 & 7.2 & 2.82 & 14.8 & 2.65 & 2.65 & 36.3 & 525 & 1 & 1 & 14.46 \\
\hline
\end{tabular}

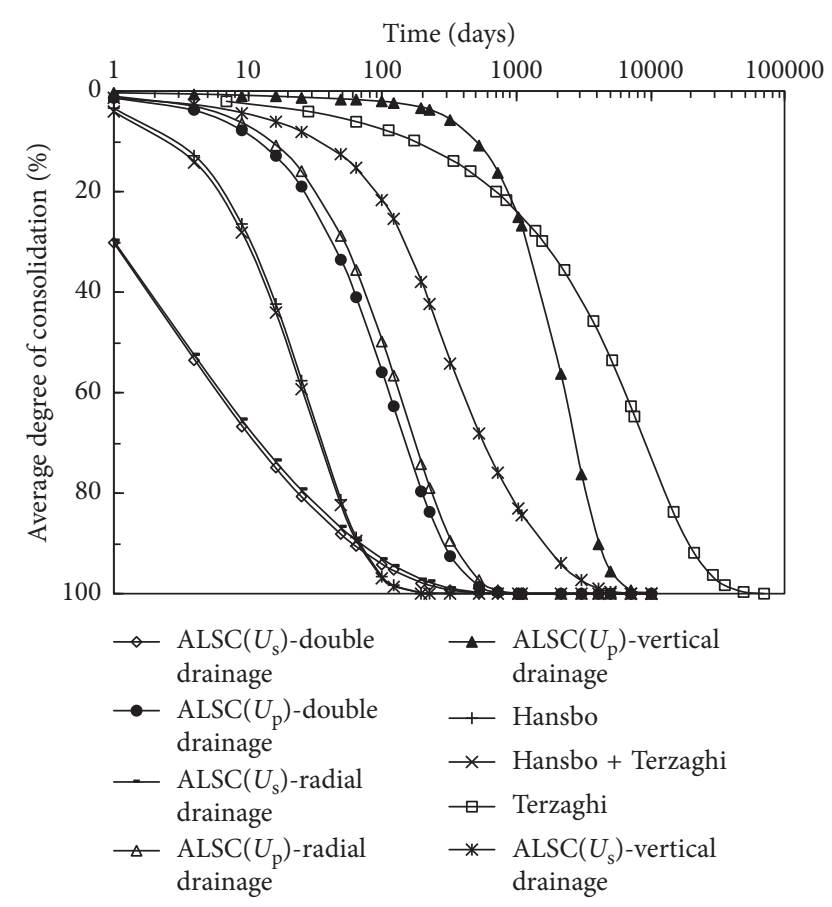

FIGURE 5: The average consolidation degree versus time for largestrain and small-strain consolidation theories.

consolidation time is 15 and 4 times those of the ALSC theory, respectively.

(2) The difference of radial consolidation. The development of consolidation by Hansbo is always faster than ALSC $\left(U_{\mathrm{p}}\right)$-radial drainage consolidation. This is because Hansbo's radial permeability coefficient is constant, while the ALSC $\left(U_{p}\right)$-radial permeability coefficient decreases with time. When the degree of consolidation is less than $90 \%$, Hansbo's solution is smaller than ALSC $\left(U_{\mathrm{s}}\right)$-radial drainage value; after $90 \%$ consolidation degree, the two are closer. This is mainly because ALSC $\left(U_{s}\right)$ considers the vertical geometrical nonlinearities, and settlement changes faster before $90 \%$ consolidation. In the consolidation stability time, taking the degree of consolidation of $80 \%$ as an example, Hansbo's small-strain consolidation time requires 47 days, while the time required for $U_{s}$ and $U_{\mathrm{p}}$ calculated by the ALSC model considering only radial flows are 27 days and 234 days, respectively. The large-strain consolidation time is $1 / 1.7$ times and 5 times that of the small-strain theory, respectively.

(3) The degree of consolidation for ALSC-double drainage in this case is like that for ALSC-radial drainage. However, the degree of consolidation for ALSC-vertical drainage is much smaller than that for
ALSC-radial drainage. It shows that when laying vertical drainage boards for working condition C, drainage path is shortened significantly, and radial soil consolidation (flows) occurs mainly in the soil. "Hansbo" solution is consistent with "Hansbo +Terzaghi" solution, and "Terzaghi" solution is much smaller than "Hansbo" solution, which also illustrates this point.

(4) In small-strain consolidation theory, the degrees of consolidation defined by stress and by strain are the same due to the assumption of microdeformation. In the ALSC theory, material nonlinearity and geometric nonlinearity are considered. In the same consolidation time, development of $U_{s}$ has always been faster than $U_{\mathrm{p}}[20]$. Thus, the dissipation rate of excess pore water pressure always lags the settlement deformation rate. If the settlement is used as the guidance in the construction process, it will overestimate the shear strength of the soil.

\section{Effect of Self-Weight on Large-Strain Consolidation Behavior under the ALSC Model}

To discuss the effect of self-weight on large-strain consolidation behavior, let $G_{\mathrm{s}}=1$ (self-weight is not considered) and $G_{s} \neq 1$ (self-weight is considered). Figure 6 shows the effect of self-weight on the degree of consolidation of double drainage and radial flows only. It can be seen that, in the case of $G_{s}=1$ and $G_{s} \neq 1$, development of the average consolidation degree with double drainage is basically similar to that with radial flows only. Therefore, the time-course curve of coupled radial and vertical flows is not drawn in Figure 7 in order to clearly reflect the effect of self-weight on the degree of consolidation.

Figure 7 shows that when only radial flows occur, compared with the consolidation rate when $G_{s}=1$, the consolidation rate of $U_{s}$ when $G_{s} \neq 1$ is faster. The error between the two is $16 \%$ on the first day and is less than $10 \%$ on the fourth day. The consolidation curve basically coincided after 100 days. The $U_{p}$ curves, comparing the situation where self-weight is considered versus the situation where it is not, basically coincided.

For large-strain consolidation where only vertical flows occur, the degree of consolidation of $U_{s}$ and $U_{p}$ with considering self-weight is faster than those without considering it. Therefore, for this kind of unconsolidated soil with high water content, the self-weight stress has little effect on the radial consolidation degree. However, self-weight has some effects on the degree of vertical consolidation. If the self-weight of the soil is neglected, the settlement rate of the soil and the dissipation rate of excess pore water pressure are underestimated $[35,36]$. 


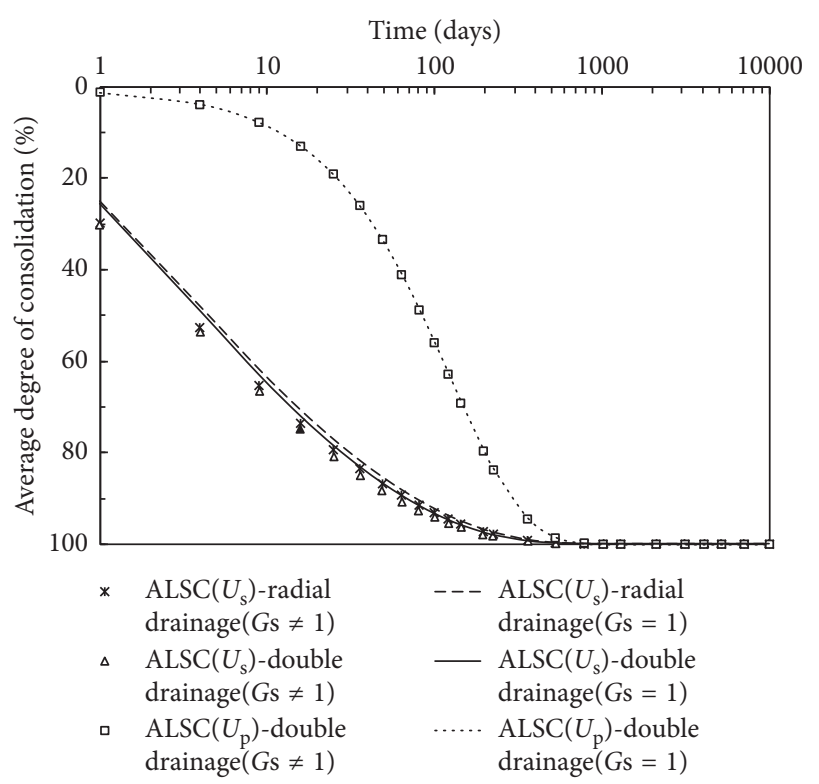

FIgURE 6: Effect of self-weight on the degree of consolidation of double drainage and radial flows only.

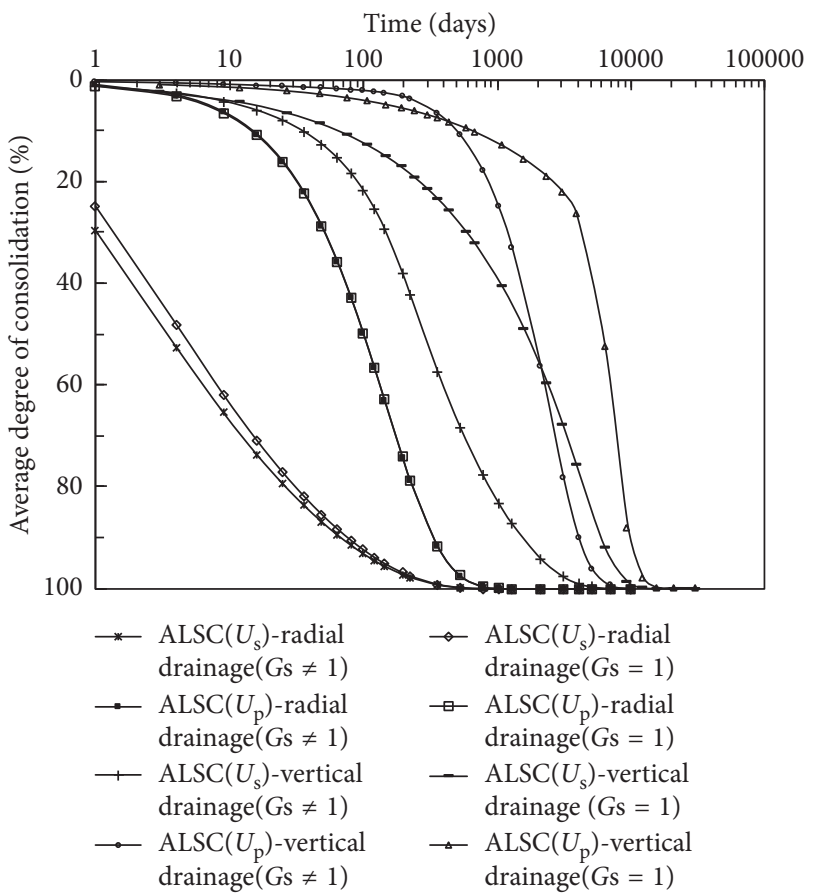

Figure 7: Effect of self-weight on the average degree of consolidation of radial flows only and vertical flows only.

\section{Change Law of Void Ratio and Excess Pore Water Pressure with Soil Height and Consolidation Time}

The variations of the void ratio and excess pore water pressure along the soil height are shown in Figures 8 and 9. As the consolidation time increases, the void ratio gradually decreases. When only vertical flows occur (Figure 8), the change rate of the void ratio varies greatly at different depths.

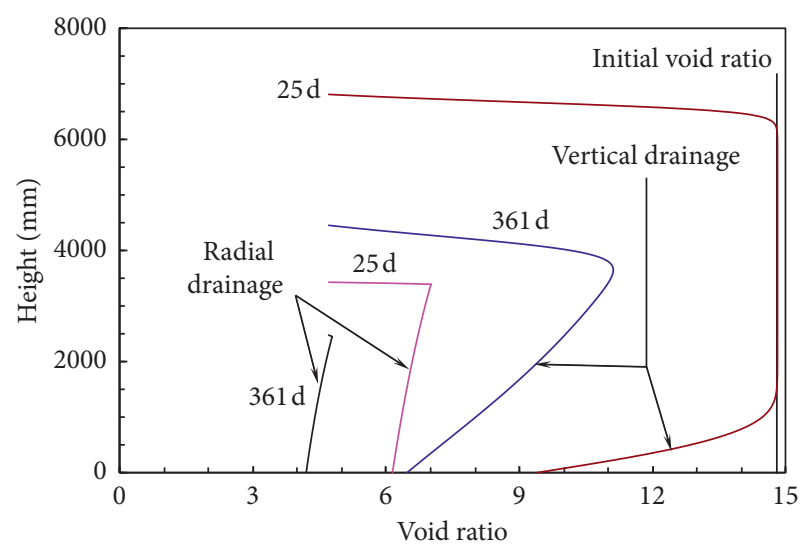

FIGURE 8: Curve of the void ratio along soil height under different consolidation time.

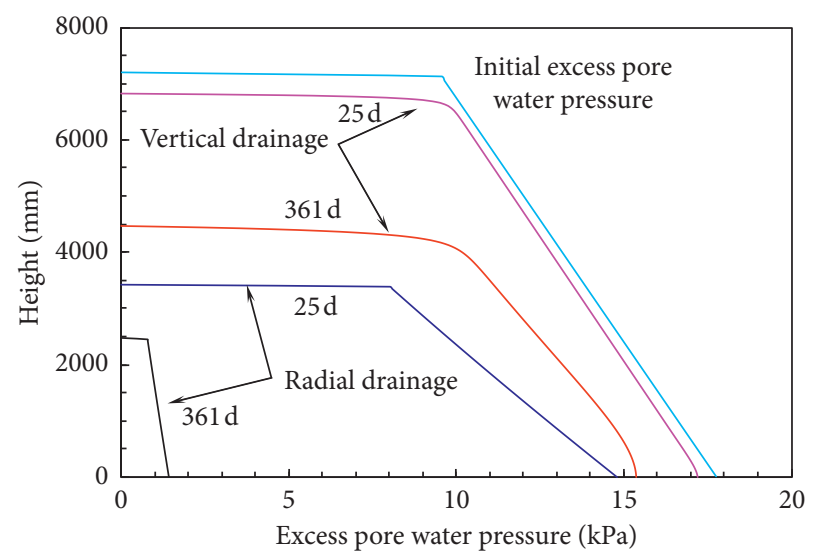

FIGURE 9: Curve of excess pore water pressure along soil height under different consolidation time.

Under the effect of external load and self-weight, the consolidation rate in the middle of the soil lags than that of the upper and lower parts [35]. When only radial flows occur, the void ratio is uniform along the height. In the same consolidation time, the reduction rate of the void ratio for radial flows only is faster than that of the vertical flows only, indicating that the arrangement of vertical drainage body can shorten the drainage path and accelerate soil consolidation rate.

From the change law of excess pore water pressure, it can be seen that, after the arrangement of the vertical drainage body, although the excess pore pressure of the soil at different depths is evenly dissipated, excess pore pressure along the depth is linearly increasing which is affected by the selfweight when only radial flows occur. However, distribution of the excess pore water pressure along the depth shows nonlinearity when only vertical flows occur. Like the change law of the void ratio, the dissipation rate of the excess pore pressure in the middle is slower than those in the upper and lower parts. From this point of view, radial flows significantly accelerate the dissipating rate of excess pore water pressure. For example, when the consolidation time is 361 days, the excess pore water pressure at the bottom of the soil when only radial flows occur is $1.5 \mathrm{kPa}$ but when only 
TABLE 2: Comparison of calculation results for consolidation of working condition C [30].

\begin{tabular}{|c|c|c|c|c|c|c|c|}
\hline \multirow{2}{*}{ Predictor } & \multirow{2}{*}{ Program } & \multirow{2}{*}{ Number of layers } & \multirow{2}{*}{ Final height (ft) } & \multirow{2}{*}{ Time (days) } & \multicolumn{3}{|c|}{ One-year profile } \\
\hline & & & & & Height (ft) & Base, $e$ & Base, $u$ (psf) \\
\hline $\mathrm{B} \& \mathrm{CI}$ & QSUS3, QSNS2 & 100 & 8.0 & Infinite & 17.0 & 6.49 & 324.5 \\
\hline $\mathrm{B} \& \mathrm{CI}$ & ULTDRAIN & - & - & - & - & - & - \\
\hline N’Wstrn & - & - & 8.8 & 2,460 & 18.5 & - & - \\
\hline UF & QSUS & 50 & 17.8 & Infinite & 16.8 & 6.09 & 323.1 \\
\hline UF & QSUS & 500 & 8.0 & Infinite & 14.7 & 6.44 & 322.9 \\
\hline UF & C. FORM & - & 8.0 & Infinite & - & - & - \\
\hline WES & PCDDF & 500 & 8.1 & 9,700 & 14.9 & 6.45 & 322.1 \\
\hline UCONN & - & 20 & 8.2 & 5,206 & 15.6 & 6.47 & 323.1 \\
\hline A and assoc & SLUQUIS & 100 & 8.0 & 1,642 & 14.7 & 6.44 & 323 \\
\hline McGill & - & 10 & 8.6 & 3,650 & 14.9 & 6.40 & 326 \\
\hline UF & UF-McGS & 20 & 8.1 & 6,476 & 14.8 & 6.44 & 325.3 \\
\hline TAGA & TAILS & 40 & 8.6 & 5,174 & 14.3 & 6.60 & 323 \\
\hline ALSC of this paper & 100 & $8.0 /(2446 \mathrm{~mm})$ & Infinite & $14.7 /(4468 \mathrm{~mm})$ & 6.47 & $321.2 /(15.38 \mathrm{kPa})$ & - \\
\hline Average & - & - & 8.2 & - & 15.6 & 6.44 & 323.7 \\
\hline
\end{tabular}

vertical flows occur is approximately $15 \mathrm{kPa}$ (10 times larger than the values of the previous case).

Table 2 summarizes the pertinent data and statistics of nine research institutes [30] and model ALSC (vertical flows only) for Scenario C. The final average thickness of soil and other consolidation parameters after one year of nine research institutes are close to those of the model ALSC, which confirms that it is a reasonable model and good precision for soil or dredged sludge at high water content.

\section{Conclusions}

In this paper, based on the ALSC model under equal strain conditions (established by Cao et al. [28]), the consolidation behavior of soils with high water content considering selfweight was investigated, and the following conclusions are obtained:

(1) The theoretical values obtained from Terzaghi's onedimensional small-strain consolidation degree are always less than those obtained from $\operatorname{ALSC}\left(U_{\mathrm{s}}\right)$-vertical drainage. Terzaghi's solution overestimates the dissipation rate of excess pore water pressure in the earlier consolidation stage and underestimates it during the later consolidation stage. Terzaghi's solution overestimates the consolidation time of soil.

(2) In the axisymmetric large-strain system and the smallstrain theory system, the vertical drainage body can shorten the drainage path, and the consolidation of soils with high water content is dominated by radial flows. At the same consolidation time, the average degree of consolidation obtained from Hansbo's theory is smaller than the values of $\operatorname{ALSC}\left(U_{s}\right)$-radial drainage, but it is higher than values obtained from $\operatorname{ALSC}\left(U_{\mathrm{p}}\right)$-radial drainage. In the ALSC model, development of $U_{\mathrm{s}}$ is always faster than $U_{\mathrm{p}}$.

(3) For the unconsolidated soil with high water content, the effect of self-weight stress on axisymmetric large-strain radial consolidation is small, but on one-dimensional large-strain vertical consolidation, it is large.
(4) In one-dimensional large-strain consolidation, the consolidation rate in the middle of the soil lags than those in the upper and lower parts under the combined action of external load and self-weight. The vertical drainage body can evenly dissipate the excess pore water pressure and accelerate the consolidation rate. Affected by the self-weight, the void ratio and the excess pore water pressure are distributed linearly along the soil. The calculation results based on the ALSC model are close to the average statistics of the nine institutions, which verifies the accuracy and applicability of the ALSC model and the difference solution method.

\section{Data Availability}

The data used to support the findings of this study are available from the corresponding author upon request.

\section{Conflicts of Interest}

The authors declare that they have no conflicts of interest.

\section{Acknowledgments}

This research was supported by the Natural National Science Foundation of China (Grant no. 51608312) and Scientific Research Foundation of Shandong University of Science and Technology for Recruited Talents (Grant no. 2016RCJJ021).

\section{References}

[1] R. A. Barron, "Consolidation of fine-grained soils by drain wells," Transactions of American Society for Civil Engineers, vol. 113, pp. 718-754, 1948.

[2] Y. B. Deng, K. H. Xie, and M. M. Lu, "Consolidation by vertical drains when the discharge capacity varies with depth and time," Computers and Geotechnics, vol. 48, pp. 1-8, 2013.

[3] S. Hansbo, "Consolidation of fine-grained soils by prefabricated drains," in Proceedings of 10th International Conference on Soil Mechanics and Foundation Engineering, 
vol. 3, pp. 677-682, Balkema, Rotterdam, Netherlands, June 1981.

[4] C. Y. Ong, J. C. Chai, and T. Hino, "Degree of consolidation of clayey deposit with partially penetrating vertical drains," Geotextiles and Geomembrances, vol. 34, pp. 19-27, 2012.

[5] H. Yoshikuni and H. Nakanodo, "Consolidation of soils by vertical drain wells with finite permeability," Soils and Foundations, vol. 14, no. 2, pp. 35-46, 1974.

[6] B. Guo, Y. Han, X. N. Gong, and M. M. Lu, "Consolidation analysis with vertical drains and general time-dependent loading," Journal of Central South University (Science and Technology), vol. 43, no. 6, pp. 2369-2377, 2012, in Chinese.

[7] G. H. Lei, Q. Zheng, C. W. W. Ng et al., "An analytical solution for consolidation with vertical drains under multiramp loading," Geotechnique, vol. 65, no. 7, pp. 531-547, 2017.

[8] C. J. Leo, "Equal strain consolidation by vertical drains," Journal of Geotechnical and Geoenvironmental Engineering, vol. 130, no. 3, pp. 316-327, 2004.

[9] M. M. Lu, K. H. Xie, and S. Y. Wang, "Consolidation of vertical drain with depth-varying stress induced by multistage loading," Computers and Geotechnics, vol. 38, pp. 1096-1101, 2011.

[10] G. F. Zhu and J. H. Yin, "Consolidation of soil with vertical and horizontal drainage under ramp load," Geotechnique, vol. 51, no. 4, pp. 361-367, 2001.

[11] B. Indraratna, C. Rujikiatkamjorn, and I. Sathananthan, "Radial consolidation of clay using compressibility indices and varying horizontal permeability," Canadian Geotechinical Journal, vol. 42, no. 5, pp. 1330-1341, 2005.

[12] M. M. Lu, S. Y. Wang, S. W. Sloan, D. C. Sheng, and K. H. Xie, "Nonlinear consolidation of vertical drains with coupled radial-vertical flow considering well resist," Geotextiles and Geomembranes, vol. 43, no. 2, pp. 182-189, 2015.

[13] R. Walker, B. Indraratna, and C. Rujikiatkamjorn, "Vertical drain consolidation with non-Darcian flow and void ratio dependent compressibility and permeability," Geotechnique, vol. 62, no. 11, pp. 985-997, 2012.

[14] X. Geng, B. Indraratna, and C. Rujikiatkamjorn, "Effectiveness of partially penetrating vertical drains under a combined surcharge and vacuum preloading," Canadian Geotechnical Journal, vol. 48, no. 6, pp. 970-983, 2011.

[15] B. Indraratna, I. Sathananthan, C. Rujikiatkamjorn, and A. S. Balasubramaniam, "Analytical and numerical modeling of soft soil stabilized by prefabricated vertical drains incorporating vacuum preloading," International Journal of Geomechanics, vol. 5, no. 2, pp. 114-124, 2005.

[16] B. Indraratna, M. E. Kan, D. Potts, C. Rujikiatkamjorn, and S. W. Sloan, "Analytical solution and numerical simulation of vacuum consolidation by vertical drains beneath circular embankments," Computers and Geotechnics, vol. 80, pp. 8396, 2016.

[17] W. H. Zhou, T. M. H. Lok, L. S. Zhao, G. X. Mei, and X. B. Li, "Analytical solutions to the axisymmetric consolidation of a multi-layer soil system under surcharge combined with vacuum preloading," Geotextiles and Geomembranes, vol. 45, no. 5, pp. 487-498, 2017.

[18] X. W. Tang, B. Niu, G. C. Cheng, and H. Shen, "Closed-form solution for consolidation of three-layer soil with a vertical drain system," Geotextiles and Geomembranes, vol. 36, pp. 81-91, 2013.

[19] J. C. Liu, G. H. Lei, and M. X. Zheng, "General solutions for consolidation of multilayered soil with a vertical drain system," Geotextiles and Geomembranes, vol. 42, no. 3, pp. 267-276, 2014.
[20] H. H. Jiang, Y. P. Zhao, G. N. Liu, and W. B. Zhao, "Large strain consolidation of soft ground with vertical drains," Chinese Journal of Geotechnical Engineering, vol. 33, no. 2, pp. 302-308, 2011, in Chinese.

[21] P. J. Fox, M. D. Nicola, and D. W. Quigley, "Piecewise-linear model for large strain radial consolidation," Journal of Geotechnical and Geoenvironmental Engineering, vol. 129, no. 10, pp. 940-950, 2003.

[22] B. Indraratna, R. Zhong, P. J. Fox, and C. Rujikiatkamjorn, "Large-strain vacuum-assisted consolidation with nondarcian radial flow incorporating varying permeability and compressibility," Journal of Geotechnical and Geoenvironmental Engineering, vol. 143, no. 1, article 04016088, 2017.

[23] M. Zhang, Y. M. Zhao, G. N. Liu, and R. H. Hu, "Finite difference solution to equation for large-strain consolidation of double-layered vertical drain ground," Chinese Journal of Geotechnical Engineering, vol. 35, no. 9, pp. 1666-1674, 2013, in Chinese.

[24] Y. Y. Hu, W. H. Zhou, and Y. Q. Cai, "Large-strain elastic viscoplastic consolidation analysis of very soft clay layers with vertical drains under preloading," Canadian Geotechnical Journal, vol. 51, no. 2, pp. 144-157, 2014.

[25] L. Q. Sun, T. Q. Jia, S. W. Yan, J. X. Lu, C. X. Yue, and Y. Y. Kang, "Study on consolidation theory of foundation with partially penetrated sand wells based on large strain," Chinese Journal of Rock Mechanics and Engineering, vol. 36, no. 2, pp. 504-512, 2017, in Chinese.

[26] G. X. Li, Advanced Soil Mechanics (Second Edition), Tsinghua University Press, Beijing, China, 2016, in Chinese.

[27] A. Onoue, "Consolidation by vertical drains taking well resistance and smear into consideration," Soils and Foundations, vol. 28, no. 4, pp. 165-174, 1988.

[28] Y. P. Cao, Z. J. Sun, J. W. Ding, and F. Ji, “Axisymmetric largestrain consolidation model for dredged clay with high water content," Chinese Journal of Geotechnical Engineering, vol. 38, no. 10, pp. 1904-1910, 2016, in Chinese.

[29] Y. P. Cao, J. W. Ding, Z. H. Ma, and Z. T. Zhang, "Axisymmetric large-strain consolidation model for dredged clay with high water content under vacuum preloading," Journal of Southeast University (Nature Science Edition), vol. 46, no. 4, pp. 860-865, 2016, in Chinese.

[30] F. C. Townsend and M. C. McVay, "SOA: Large strain consolidation predictions," Journal of Geotechnical Engineering, vol. 116, no. 2, pp. 222-243, 1990.

[31] R. E. Gibson, G. L. England, and M. J. Hussey, "The theory of one-dimensional soil consolidation of saturated clays, I. Finite nonlinear consolidation of thin homogeneous layers," Geotechnique, vol. 17, no. 3, pp. 261-273, 1967.

[32] R. E. Gibson, R. L. Schiffman, and K. W. Cargill, "The theory of one-dimensional soil consolidation of saturated clays, II. Finite nonlinear consolidation of thick homogeneous layers," Canadian Geotechnical Journal, vol. 18, no. 3, pp. 280-293, 1981.

[33] S. Hansbo, "Conslidation of clay by band-shaped prefabricated drains," Ground Engineering, vol. 12, no. 5, pp. 16-25, 1979.

[34] B. H. Li, H. W. Ying, K. H. Xie, and G. X. Zeng, "Analysis of 1D large-strain consolidation considering the self-weight of soil," China Civil Engineering Journal, vol. 33, no. 3, pp. 54-59, 2000, in Chinese.

[35] H. H. Jiang, G. N. Liu, and Y. M. Zhao, “A solution of Gibson's governing equation of one-dimensional consolidation," 
Chinese Journal of Geotechnical Engineering, vol. 32, no. 5, pp. 745-750, 2010, in Chinese.

[36] X. Y. Xie, J. Q. Huang, W. J. Wang, and J. Z. Li, "Influence of weight of soils on nonlinear finite strain consolidation for Ningbo soft clay," Journal of Zhenjiang University Engineering Science, vol. 48, no. 5, pp. 827-834, 2014, in Chinese. 


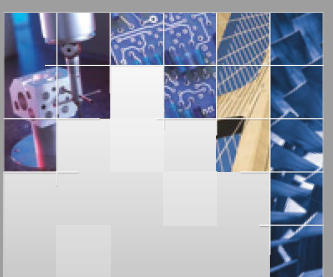

\section{Enfincering}
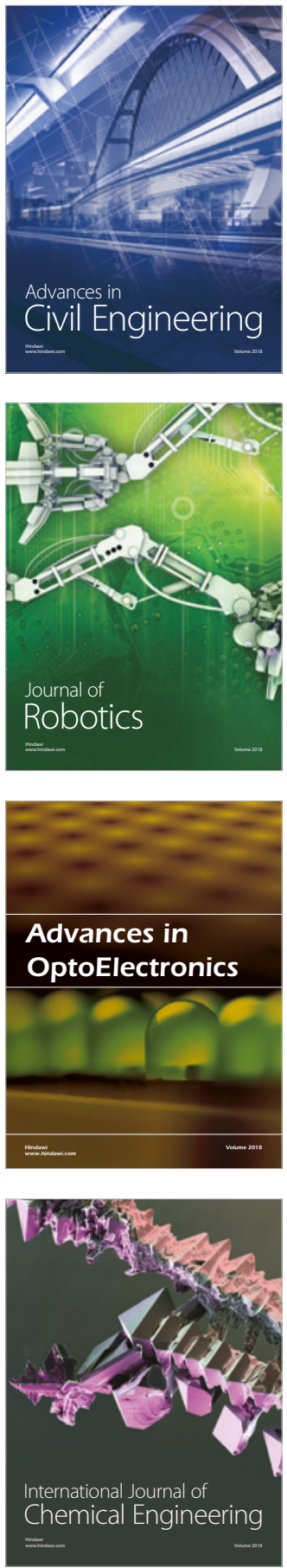

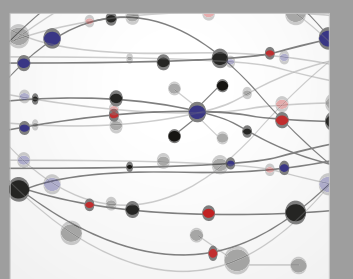

\section{Rotating \\ Machinery}

The Scientific World Journal

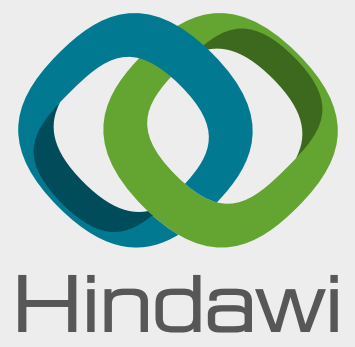

Submit your manuscripts at

www.hindawi.com
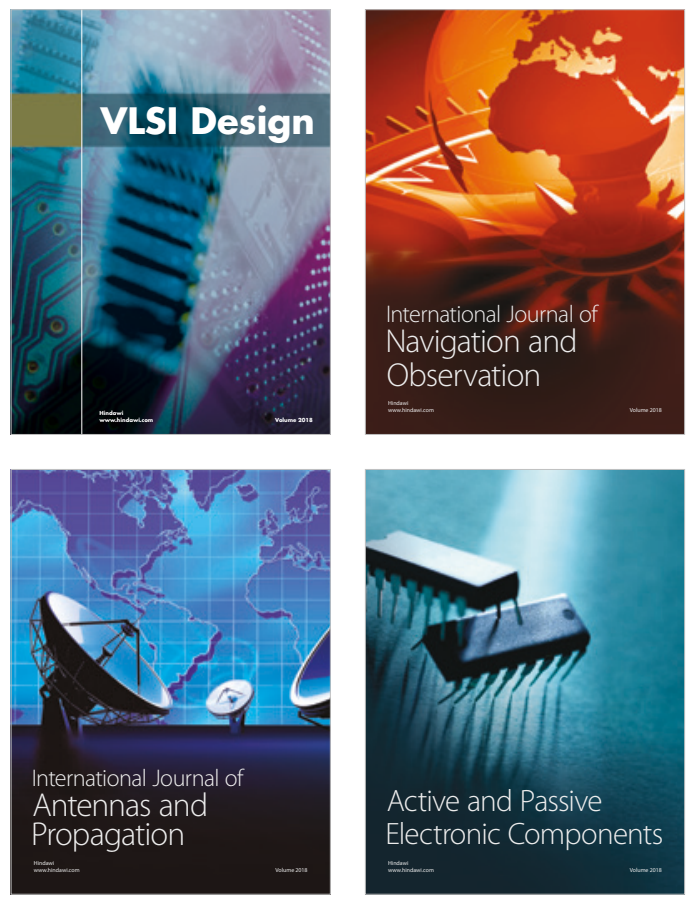
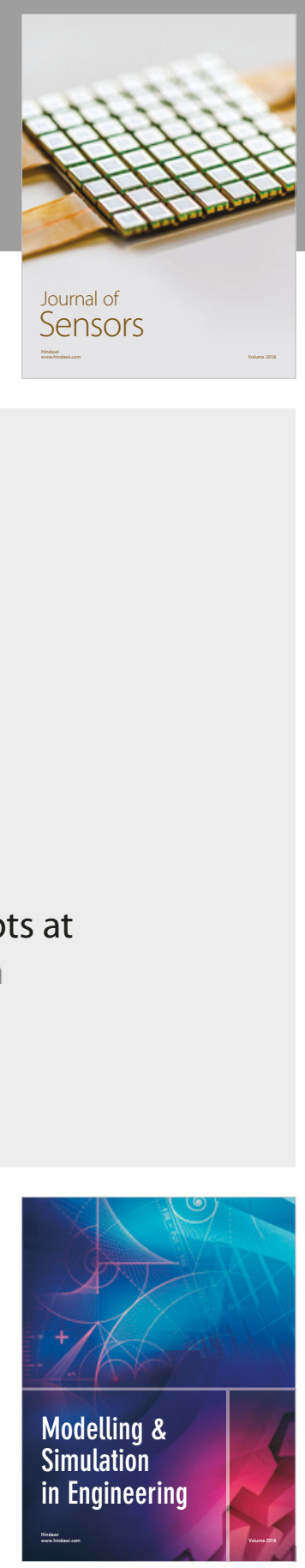

\section{Advances \\ Multimedia}
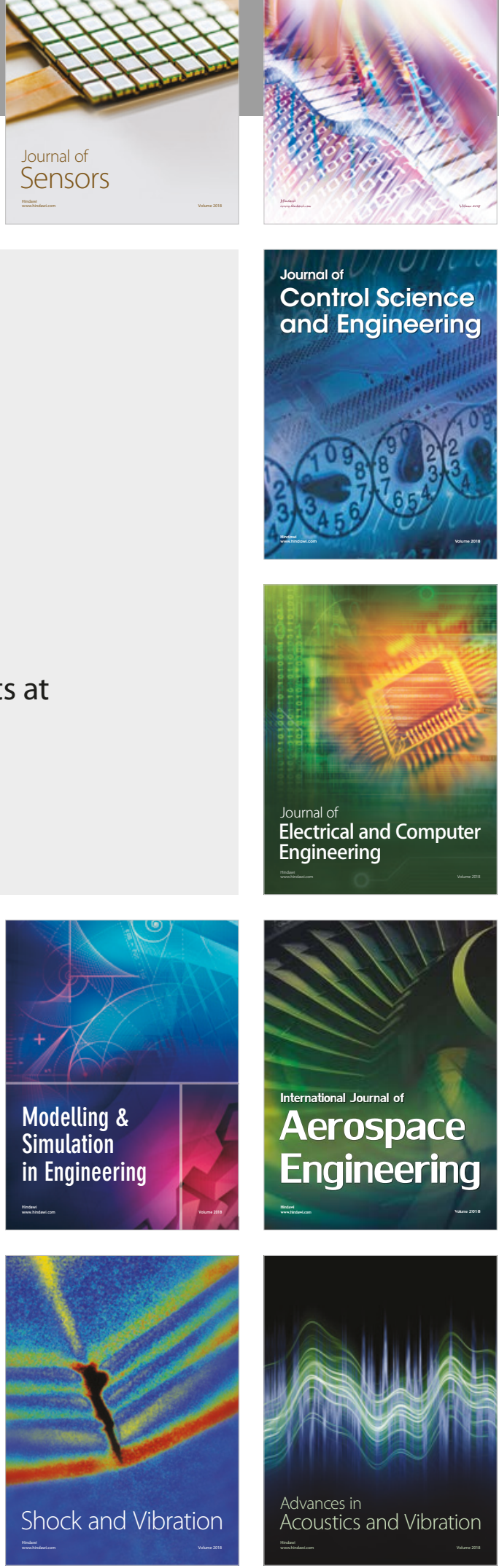